\title{
Thermodynamic Assessment of the Al-Mn and Mg-Al-Mn Systems
}

Adarsh Shukla and Arthur D. Pelton

\author{
(Submitted May 5, 2008; in revised form July 16, 2008)
}

\begin{abstract}
The binary Al-Mn system has been critically evaluated based upon available phase equilibrium and thermodynamic data, and optimized model parameters have been obtained giving the Gibbs energies of all phases as functions of temperature and composition. The liquid solution has been modeled with the modified quasichemical model to account for short-range ordering. The results have been combined with those of our previous optimizations of the Al-Mg and Mg-Mn systems to evaluate and optimize the Mg-Al-Mn system. All available data for the ternary system are reproduced with only one small ternary model parameter for the liquid phase.
\end{abstract}

Keywords aluminum, magnesium, manganese, phase diagrams, thermodynamics

\section{Introduction}

Although magnesium-based materials have a long history of important commercial applications, including automotive, there remains much to be learned about the basic properties of the metal and its alloys. With the recent renewed interest in lightweight wrought materials, including both sheet and tube applications, there has been an increased focus on developing a better understanding of novel magnesium alloys, including those that incorporate additions of $\mathrm{Mn}$ and $\mathrm{Al}$. These alloy systems, along with other potential candidates, are being actively pursued as possible routes to develop magnesium materials with improved ductility, or even practical room temperature formability.

The properties of cast or wrought material depend first and foremost upon the phases and microstructural constituents (eutectics, precipitates, solid solutions, etc.) which are present. In an alloy with several alloying elements, the phase relationships are very complex. In order to investigate and understand these complex phase relationships effectively, it is very useful to develop thermodynamic databases containing model parameters giving the thermodynamic properties of all phases as functions of temperature and composition. Using Gibbs free energy minimization software such as FactSage, ${ }^{[1,2]}$ the automotive and aeronautical industries and their suppliers will be able to access the databases to calculate the amounts and compositions of all phases at equilibrium at any temperature and composition in multicomponent alloys, to follow the course of equilibrium

Adarsh Shukla, and Arthur D. Pelton, Département de Génie Chimique, Centre de Recherche en Calcul Thermochimique, Ecole Polytechnique, Montréal, Québec, Canada. Contact e-mail: apelton@ polymtl.ca. or non-equilibrium cooling, to calculate corresponding heat effects, etc.

Such thermodynamic databases are prepared by critical evaluation, modeling, and optimization. In a thermodynamic "optimization," adjustable model parameters are calculated using, simultaneously, all available thermodynamic and phase-equilibrium data in order to obtain one set of model equations as functions of temperature and composition. Thermodynamic data, such as activities, can aid in the evaluation of the phase diagrams, and information on phase equilibria can be used to deduce thermodynamic properties. Thus, it is frequently possible to resolve discrepancies in the available data. From the model equations, all of the thermodynamic properties and phase diagrams can be back-calculated, and interpolations and extrapolations can be made in a thermodynamically correct manner. The data are thereby rendered self-consistent and consistent with thermodynamic principles, and the available data are distilled into a small set of model parameters, ideal for computer storage.

As part of a broader research project to develop a thermodynamic database for $\mathrm{Mg}$-alloys containing up to 25 potential alloying elements, the present study reports on evaluations and optimizations of the Al-Mn and Mg-Al-Mn systems. Previous optimizations ${ }^{[3-5]}$ were based upon a Bragg-Williams (BW) random-mixing model for the liquid phase. However, the liquid phase in the Al-Mn binary system is expected to exhibit short-range ordering (SRO) as evidenced by the relatively large negative enthalpy of mixing. ${ }^{[6]}$ As has been shown by the present authors, ${ }^{[7]}$ the use of the BW model in liquids with a high degree of SRO generally results in unsatisfactory results and in poor predictions of ternary properties from binary model parameters. Hence the Al-Mn system was reoptimized with the modified quasichemical model (MQM) for the liquid phase; the present optimization reproduces all available data in the ternary Mg-Al-Mn system with only one very small ternary model parameter for the liquid solution. Care was taken to ensure that all optimized properties, such as the entropies of formation of intermetallic compounds, have physically reasonable values. 


\section{Modified Quasichemical Model}

The MQM in the pair approximation ${ }^{[8]}$ was used to model the liquid Al-Mn alloys. The liquid phases in the $\mathrm{Mg}-\mathrm{Al}$ and Mg-Mn sub-systems of the Mg-Al-Mn system were also modeled previously with the MQM. ${ }^{[9,10]}$ This model, which takes SRO into account, has been used extensively for molten salts, ${ }^{[11-13]}$ slags ${ }^{[14]}$ and sulfides. ${ }^{[15-17]}$ All details of the model and notation have been described previously ${ }^{[8]}$ and only a brief summary is given here.

In the MQM in the pair approximation, the following pair exchange reaction between atoms $A$ and $B$ on neighboring lattice sites is considered:

$$
(A-A)+(B-B)=2(A-B) ; \quad \Delta g_{A B}
$$

where $(i-j)$ represents a first-nearest-neighbor pair. The non-configurational Gibbs energy change for the formation of two moles of $(A-B)$ pairs is $\Delta g_{A B}$.

Let $n_{A}$ and $n_{B}$ be the number of moles of $A$ and $B, n_{i j}$ be the number of moles of $(i-j)$ pairs, and $Z_{A}$ and $Z_{B}$ be the coordination numbers of $A$ and $B$. The pair fractions, mole fractions, and "coordination-equivalent" fractions are defined respectively as:

$X_{i j}=\frac{n_{i j}}{n_{A A}+n_{B B}+n_{A B}}$

$X_{A}=\frac{n_{A}}{n_{A}+n_{B}}=1-X_{B}$

$Y_{A}=\frac{Z_{A} n_{A}}{Z_{A} n_{A}+Z_{B} n_{B}}=\frac{Z_{A} X_{A}}{Z_{A} X_{A}+Z_{B} X_{B}}=1-Y_{B}$

The following equations may be written:

$Z_{A} X_{A}=2 n_{A A}+n_{A B}$

$Z_{B} X_{B}=2 n_{B B}+n_{A B}$

The Gibbs energy of the solution is given by:

$G=\left(n_{A} g_{A}^{\circ}+n_{B} g_{B}^{\circ}\right)-T \Delta S^{\text {config }}+\left(\frac{n_{A B}}{2}\right) \Delta g_{A B}$

where $g_{A}^{\circ}$ and $g_{B}^{\circ}$ are the molar Gibbs energies of the pure components, and $\Delta S^{\text {config }}$ is the configurational entropy of mixing given by randomly distributing the $(A-A),(B-B)$ and $(A-B)$ pairs in the one-dimensional Ising approximation: ${ }^{[8]}$

$$
\begin{aligned}
\Delta S^{\text {config }}=- & R\left(n_{A} \ln X_{A}+n_{B} \ln X_{B}\right) \\
-R & {\left[n_{A A} \ln \left(\frac{X_{A A}}{Y_{A}^{2}}\right)+n_{B B} \ln \left(\frac{X_{B B}}{Y_{B}^{2}}\right)\right.} \\
& \left.+n_{A B} \ln \left(\frac{X_{A B}}{2 Y_{A} Y_{B}}\right)\right]
\end{aligned}
$$

$\Delta g_{A B}$ is expanded in terms of the pair fractions:

$$
\Delta g_{A B}=\Delta g_{A B}^{\circ}+\sum_{i \geq 1} g_{A B}^{i 0} X_{A A}^{i}+\sum_{j \geq 1} g_{A B}^{0 j} X_{B B}^{j}
$$

where $\Delta g_{A B}^{\circ}, g_{A B}^{i 0}$ and $g_{A B}^{0 j}$ are the parameters of the model which can be functions of temperature.

The equilibrium pair distribution is calculated by setting

$$
\left(\frac{\partial G}{\partial n_{A B}}\right)_{n_{A}, n_{B}}=0
$$

This gives the "equilibrium constant" for the "quasichemical reaction" of Eq 1:

$\frac{X_{A B}^{2}}{X_{A A} X_{B B}}=4 \exp \left(-\frac{\Delta g_{A B}}{R T}\right)$

As $\Delta g_{A B}$ becomes progressively more negative, the reaction (Eq 1) is shifted progressively to the right, and the calculated enthalpy and configurational entropy of mixing assume, respectively, the negative " $\mathrm{V}$ " and " $\mathrm{m}$ " shapes characteristic of SRO.

The composition of maximum SRO is determined by the ratio of the coordination numbers $Z_{B} / Z_{A}$, as given by the following equations: ${ }^{[8]}$

$\frac{1}{Z_{A}}=\frac{1}{Z_{A A}^{A}}\left(\frac{2 n_{A A}}{2 n_{A A}+n_{A B}}\right)+\frac{1}{Z_{A B}^{A}}\left(\frac{n_{A B}}{2 n_{A A}+n_{A B}}\right)$

$\frac{1}{Z_{B}}=\frac{1}{Z_{B B}^{B}}\left(\frac{2 n_{B B}}{2 n_{B B}+n_{A B}}\right)+\frac{1}{Z_{B A}^{B}}\left(\frac{n_{A B}}{2 n_{B B}+n_{A B}}\right)$

where $Z_{A A}^{A}$ and $Z_{A B}^{A}$ are the values of $Z_{A}$ respectively when all the nearest neighbors of an $A$ are $A$ 's, and when all nearest neighbors of an $A$ are $B$ 's, and where $Z_{B B}^{B}$ and $Z_{B A}^{B}$ are defined similarly. (Note that $Z_{A B}^{A}$ and $Z_{B A}^{A}$ represent the same quantity and can be used interchangeably.) In order to set the composition of maximum SRO at $X_{\mathrm{Mn}}=0.5$ in the binary systems we set the $Z_{i j}^{i} / Z_{i j}^{j}=1$ so that the composition of maximum SRO occurs at the equimolar composition. Although the model is sensitive to the ratio of the coordination numbers, it is less sensitive to their absolute values. The use of the one-dimensional Ising model in Eq 8 introduces a mathematical approximation into the model which we have found, by experience, can be partially compensated by selecting values of $Z_{B}$ and $Z_{A}$ which are smaller than the actual values. The values of the coordination numbers selected in the present study are listed in Table 1. The liquid phase in the $\mathrm{Al}-\mathrm{Mg}$ and the $\mathrm{Mg}-\mathrm{Mn}$ systems show maximum SRO near the equimolar composition $^{[9,10]}$; hence $Z_{A B}^{A}=Z_{B A}^{B}$ in all cases.

From the MQM model parameters for the binary liquid phases, the thermodynamic properties of a ternary liquid phase may be estimated as discussed previously. ${ }^{[18]}$ If ternary experimental data are available, additional ternary model parameters may be added if required.

\section{The Al-Mn System}

All calculations and optimizations in the present study were performed with the FactSage thermochemical software. ${ }^{[1,2]}$ 
Table 1 Model parameters of the Al-Mn and Mg-Al-Mn systems optimized in the present study

\begin{tabular}{|c|c|c|c|c|}
\hline \multicolumn{5}{|l|}{ Liquid } \\
\hline \multicolumn{5}{|c|}{ Co-ordination numbers: $Z_{\mathrm{AlAl}}^{\mathrm{Al}}=Z_{\mathrm{MnMn}}^{\mathrm{Mn}}=Z_{\mathrm{AlMn}}^{\mathrm{Al}}=Z_{\mathrm{MnAl}}^{\mathrm{Mn}}=6$} \\
\hline \multicolumn{5}{|c|}{$\Delta g_{\mathrm{Al}-\mathrm{Mn}}:(-16945+3.012 T)+(-5857+0.418 T) X_{\mathrm{Al}-\mathrm{Al}}+(-1674+2.761 T) X_{\mathrm{Mn}-\mathrm{Mn}}$ Joules } \\
\hline \multicolumn{5}{|c|}{ Ternary interaction term for $\Delta g_{\mathrm{Al}-\mathrm{Mn}}: 0.837 T\left(\frac{X_{\mathrm{Mg}}}{X_{\mathrm{Mg}}+X_{\mathrm{Mn}}}\right)$ Joules } \\
\hline \multicolumn{5}{|l|}{ Solid solutions } \\
\hline \multicolumn{5}{|c|}{ Excess Gibbs energy terms, $G^{\mathrm{E}} / X_{\mathrm{Mn}} X_{\mathrm{Al}}, \mathrm{J} / \mathrm{mol}$ of atoms } \\
\hline \multicolumn{3}{|l|}{ CUB } & \multicolumn{2}{|c|}{$(-121838+46.861 T)+(-5021+10.627 T)\left(X_{\mathrm{Mn}}-X_{\mathrm{Al}}\right)$} \\
\hline \multicolumn{3}{|l|}{$\mathrm{CBCC}$} & \multicolumn{2}{|c|}{$(-79536+27.614 T)+(-10042)\left(X_{\mathrm{Mn}}-X_{\mathrm{Al}}\right)$} \\
\hline \multicolumn{3}{|l|}{$\mathrm{BCC}$} & \multicolumn{2}{|c|}{$(-108700+32.510 T)+(44769-19.246 T)\left(X_{\mathrm{Mn}}-X_{\mathrm{Al}}\right)$} \\
\hline \multicolumn{3}{|l|}{ FCC } & \multicolumn{2}{|c|}{$(-84517+29.999 T)+(-19665+12.552 T)\left(X_{\mathrm{Mn}}-X_{\mathrm{Al}}\right)$} \\
\hline \multicolumn{3}{|l|}{$\mathrm{HCP}$} & \multicolumn{2}{|c|}{$\begin{array}{l}(-87027+17.154 T)+(-5774+8.786 T)\left(X_{\mathrm{Mn}}-X_{\mathrm{Al}}\right)+(83931-47.279 T) \\
\left(X_{\mathrm{Mn}}-X_{\mathrm{Al}}\right)^{2}\end{array}$} \\
\hline \multicolumn{5}{|c|}{ “ $\mathrm{Al}_{8} \mathrm{Mn}_{5}$ " $\left\{\mathrm{Al}_{12} \mathrm{Mn}_{5}(\mathrm{Al}, \mathrm{Mn})_{9}\right\}, \mathrm{J} / \mathrm{mol}$ of atoms } \\
\hline \multicolumn{3}{|c|}{${ }^{0} G_{\mathrm{Al}: \mathrm{Mn}: \mathrm{Al}}$ (a) } & \\
\hline \multicolumn{3}{|l|}{${ }^{0} \mathrm{G}_{\mathrm{Al}: \mathrm{Mn}: \mathrm{Mn}}(\mathrm{a})$} & \multicolumn{2}{|c|}{$\frac{12}{26} G_{\mathrm{FCC}}^{\mathrm{ACC}}+\frac{14}{26} G_{\mathrm{CBCC}}^{\mathrm{MnCC}}+(-23566+2.502 T)$} \\
\hline \multicolumn{3}{|l|}{ Excess Gibbs energy, $G^{\mathrm{E}} / y_{\mathrm{A} 1} y_{\mathrm{Mn}}$} & \multicolumn{2}{|c|}{$(-31621+14.792 T)+(-7870+10.024 T)\left(y_{\mathrm{Mn}}-\mathrm{y}_{\mathrm{Al}}\right)(\mathrm{b})$} \\
\hline \multicolumn{5}{|l|}{ Stoichiometric compounds } \\
\hline Compounds & $\begin{array}{c}\Delta H_{298}^{0}(c) \\
\mathrm{J} / \mathrm{mol} \text { of atoms }\end{array}$ & $\begin{array}{c}S_{298}^{0}(\mathrm{~d}) \\
\mathrm{J} /[(\mathrm{mol} \text { of atoms })-\mathrm{K}]\end{array}$ & $\begin{array}{c}\Delta S_{298}^{0}(\mathrm{c}) \\
\mathrm{J} /[(\mathrm{mol} \text { of atoms })-\mathrm{K}]\end{array}$ & $C_{\mathrm{p}}, \mathrm{J} /[(\mathrm{mol}$ of atoms $)-\mathrm{K}]$ \\
\hline$\frac{1}{13} \mathrm{Al}_{12} \mathrm{Mn}$ & -8818 & 26.208 & -2.394 & $0.923 C_{\mathrm{p}}(\mathrm{Al}, \mathrm{FCC})+0.077 C_{\mathrm{p}}(\mathrm{Mn}, \mathrm{CBCC})$ \\
\hline$\frac{1}{7} \mathrm{Al}_{6} \mathrm{Mn}$ & -15714 & 25.243 & -3.617 & $0.857 C_{\mathrm{p}}(\mathrm{Al}, \mathrm{FCC})+0.143 C_{\mathrm{p}}(\mathrm{Mn}, \mathrm{CBCC})$ \\
\hline$\frac{1}{568} \lambda-\mathrm{Al}_{4} \mathrm{Mn}$ (modeled as $\mathrm{Al}_{461} \mathrm{Mn}_{107}$ ) & -20450 & 24.325 & -4.714 & $0.812 C_{\mathrm{p}}(\mathrm{Al}, \mathrm{FCC})+0.188 C_{\mathrm{p}}(\mathrm{Mn}, \mathrm{CBCC})$ \\
\hline$\frac{1}{5} \mu-\mathrm{Al}_{4} \mathrm{Mn}$ & -20880 & 24.860 & -4.224 & $0.800 C_{\mathrm{p}}(\mathrm{Al}, \mathrm{FCC})+0.200 C_{\mathrm{p}}(\mathrm{Mn}, \mathrm{CBCC})$ \\
\hline$\frac{1}{15} \mathrm{Al}_{11} \mathrm{Mn}_{4}(\mathrm{e})$ & -23913 & 25.400 & -3.946 & $0.733 C_{\mathrm{p}}(\mathrm{Al}, \mathrm{FCC})+0.267 C_{\mathrm{p}}(\mathrm{Mn}, \mathrm{CBCC})$ \\
\hline$\frac{1}{23} \mathrm{Mn}_{2} \mathrm{Mg}_{3} \mathrm{Al}_{18}(\mathbf{T})$ & -9887 & 28.391 & -0.820 & $\begin{array}{l}0.783 C_{\mathrm{p}}(\mathrm{Al}, \mathrm{FCC})+0.111 C_{\mathrm{p}}(\mathrm{Mn}, \mathrm{CBCC}) \\
\quad+0.106 C_{\mathrm{p}}(\mathrm{Mg}, \mathrm{HCP})\end{array}$ \\
\hline \multicolumn{5}{|l|}{ (a) Gibbs energy of end-members ${ }^{[42,43]}$} \\
\hline \multicolumn{5}{|c|}{ (b) $y_{\mathrm{Al}}$ and $y_{\mathrm{Mn}}$ are the site fractions of $\mathrm{Al}$ and $\mathrm{Mn}$ in the sublattcie $(\mathrm{Al}, \mathrm{Mn})_{9}$} \\
\hline \multicolumn{5}{|c|}{ (c) Enthalpy and entropy of formation from the elements at $298.15 \mathrm{~K}$} \\
\hline \multicolumn{5}{|c|}{ (d) Absolute Third-Law entropy at $298.15 \mathrm{~K}$} \\
\hline
\end{tabular}

The optimized model parameters for the binary phases are reported in Table 1 . Gibbs energies of all stable and metastable phases of the elements were taken from Dinsdale. ${ }^{[19]}$ Crystallographic data ${ }^{[20-22]}$ for the phases are listed in Table 2. The optimized phase diagram of this system is shown in Fig. 1.

McAlister and Murray ${ }^{[23]}$ presented an extensive literature review of the system up to 1987 . Jansson ${ }^{[3]}$ performed the first thermodynamic optimization of the system, treating the liquid phase with a BW random-mixing model. Liu et al. ${ }^{[4]}$ re-optimized the system in the light of their new data $^{[24]}$ for the HCP phase. Du et al. ${ }^{[5]}$ optimized the Al-Mn system as a first step in their assessment of the Mg-Al-Mn system.

The solid solution phases CBCC, CUB, FCC, BCC, $\gamma$ (BCC) and $\varepsilon$ (HCP) (Fig. 1) were modeled by a singlesublattice substitutional model. There are numerous data ${ }^{[25-34]}$ for the solubility of $\mathrm{Mn}$ in FCC-Al obtained by various techniques (electrical resistivity (ER), optical microscopy $(\mathrm{OM})$, lattice parameter (LP), hardness measurements (HD), electron probe microanalysis (EPMA)). Figure 2 compares the present optimization with these data.

The optimized phase diagram for $X_{\mathrm{Mn}} \leq 0.2$ is compared with experimental data in Fig. 3. Schaefer et al., ${ }^{[35]}$ by X-ray diffraction (XRD) and metallography, identified $\mathrm{Al}_{12} \mathrm{Mn}$ as a stable phase. They reported the pertectoid decomposition of $\mathrm{Al}_{12} \mathrm{Mn}$ into $\mathrm{Al}$ and $\mathrm{Al}_{6} \mathrm{Mn}$ between 504 and $521{ }^{\circ} \mathrm{C}$. The present calculated temperature for this reaction is $511^{\circ} \mathrm{C}$.

Dix et al. ${ }^{[34]}$ and Phillips ${ }^{[36]}$ studied the system by metallography and thermal analysis. They reported the intermetallic compounds $\mathrm{Al}_{6} \mathrm{Mn}$ and $\mathrm{Al}_{4} \mathrm{Mn}\left(\mu-\mathrm{Al}_{4} \mathrm{Mn}\right.$ in Fig. 1). Godecke and $\operatorname{Koster}^{[37]}$ studied the system by the same techniques. They confirmed the presence of $\mathrm{Al}_{11} \mathrm{Mn}_{4}$ which was also noted by Philips. ${ }^{[36]}$ They reported high- and low-temperature allotropes of $\mathrm{Al}_{11} \mathrm{Mn}_{4}$, the high-temperature form with a single-phase composition range of approximately 4 at.\%. As the exact nature of the phase boundaries of the high-temperature form are unknown, this compound is treated as two stoichiometric 
Table 2 Crystallographic data of all phases in the Mg-Al-Mn system considered in the present optimization

\begin{tabular}{|c|c|c|c|c|}
\hline Phase & Prototype & Pearson symbol & Space group & Comments \\
\hline FCC & $\mathrm{Cu}$ & $c F 4$ & $F m \overline{3} m$ & $\mathrm{Al}, \mathrm{Mn}$ are stable phases ${ }^{[22]}$ \\
\hline $\mathrm{BCC}$ & $\mathrm{W}$ & $c I 2$ & $\operatorname{Im} \overline{3} m$ & Mn is stable phase ${ }^{[22]}$ \\
\hline CUB & $\mathrm{Mn}$ & $c P 20$ & $P 4_{1} 32$ & Mn is stable phase ${ }^{[22]}$ \\
\hline $\mathrm{CBCC}$ & $\mathrm{Mn}$ & $c 158$ & $I \overline{4} 3 m$ & $\mathrm{Mn}$ is stable phase ${ }^{[22]}$ \\
\hline $\mathrm{HCP}$ & $\mathrm{Mg}$ & $h P 2$ & $\mathrm{~Pb}_{3} / m m c$ & $\mathrm{Mg}$ and $\varepsilon(\mathrm{HCP})$ phases are stable phases ${ }^{[22]}$ \\
\hline $\mathrm{Al}_{12} \mathrm{Mn}$ & $\mathrm{Al}_{12} \mathrm{~W}$ & $c I 26$ & $\operatorname{Im} 3$ & {$[22]$} \\
\hline $\mathrm{Al}_{6} \mathrm{Mn}$ & $\mathrm{Al}_{6} \mathrm{Mn}$ & $o C 28$ & $\mathrm{Cmcm}$ & [22] \\
\hline$\lambda-\mathrm{Al}_{4} \mathrm{Mn}$ & $\ldots$ & $h P 586$ & $P 6_{3} / m$ & [21] \\
\hline$\mu-\mathrm{Al}_{4} \mathrm{Mn}$ & $\mathrm{Al}_{4} \mathrm{Mn}$ & $h P 574$ & $P 6_{3} / m m c$ & [21] \\
\hline $\mathrm{Al}_{11} \mathrm{Mn}_{4}$ & $\mathrm{Al}_{11} \mathrm{Mn}_{4}$ & $a P 15$ & $P \overline{1}$ & Low temperature form ${ }^{[22]}$ \\
\hline $\mathrm{Al}_{11} \mathrm{Mn}_{4}$ & $\mathrm{Al}_{3} \mathrm{Mn}$ & $o P 156$ & $P n 2_{1} a$ & High temperature form ${ }^{[21]}$ \\
\hline " $\mathrm{Al}_{8} \mathrm{Mn}_{5} "$ & $\mathrm{Al}_{8} \mathrm{Cr}_{5}$ & $h R 26$ & $R 3 m$ & {$[20]$} \\
\hline $\mathrm{Al}_{30} \mathrm{Mg}_{23}$ & $\mathrm{Mn}_{44} \mathrm{Si}_{9}$ & $h R 159$ & $R \overline{3} h$ & [22] \\
\hline$\beta-\mathrm{AlMg}$ & $\mathrm{Al}_{3} \mathrm{Mg}_{2}$ & $c F 1168$ & $F d \overline{3} m$ & {$[22]$} \\
\hline$\gamma$-AlMg & $\mathrm{Mn}(\mathrm{CBCC})$ & cI58 & $I \overline{4} 3 m$ & [22] \\
\hline $\mathrm{Mn}_{2} \mathrm{Mg}_{3} \mathrm{Al}_{18}$ & $\mathrm{Al}_{18} \mathrm{Mg}_{3} \mathrm{Cr}_{2}$ & $c F 184$ & $F d \overline{3} m$ & [22] \\
\hline
\end{tabular}

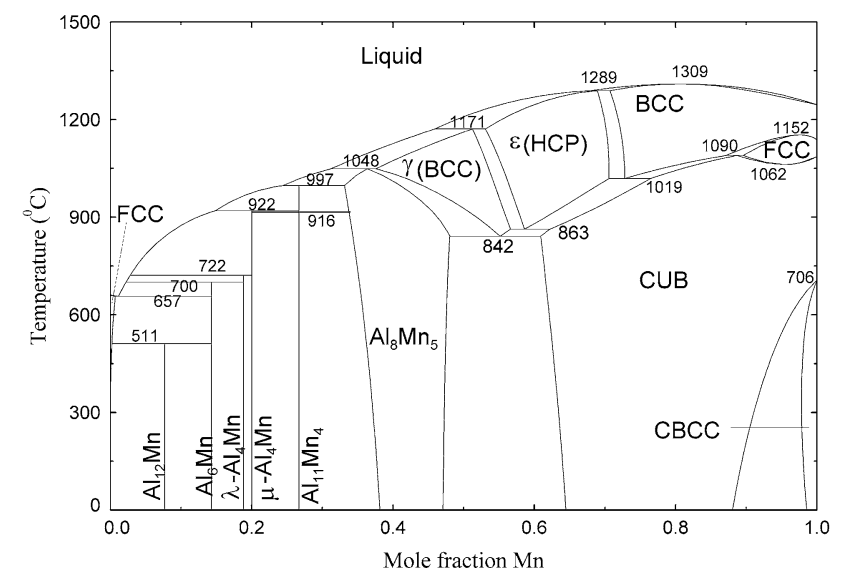

Fig. 1 Optimized phase diagram of the Al-Mn system

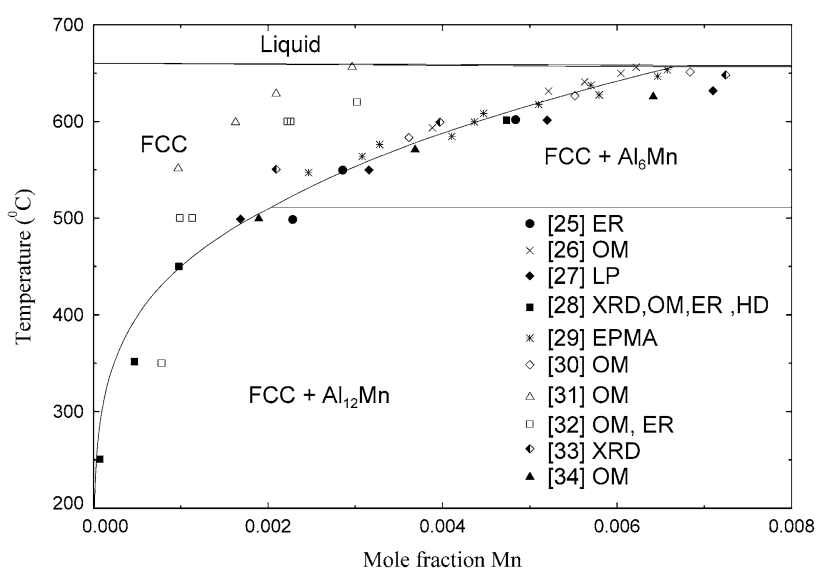

Fig. 2 Optimized solubility of Mn in the FCC phase

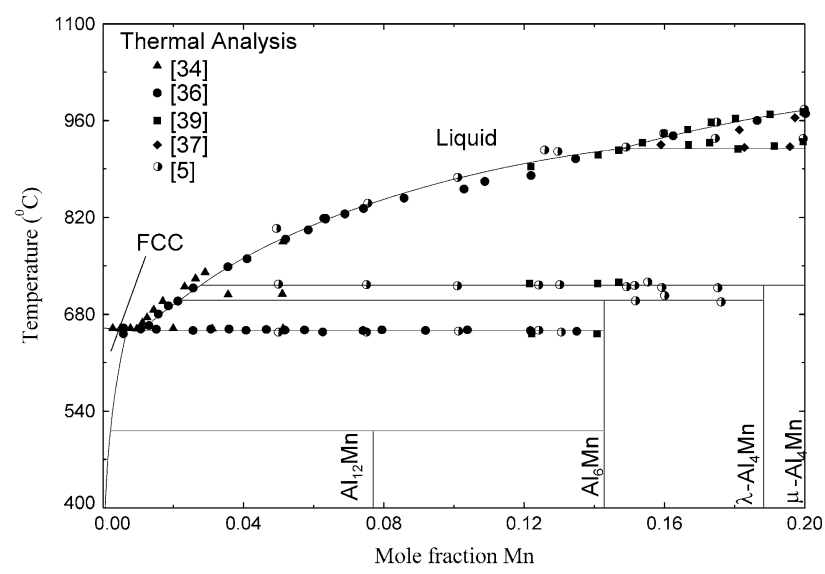

Fig. 3 Optimized phase diagram of the Al-Mn system for $X_{\mathrm{Mn}} \leq 0.2$

phases $\mathrm{Al}_{11} \mathrm{Mn}_{4}$ in the present calculations with a transition temperature of $916^{\circ} \mathrm{C} .{ }^{[37]}$ In the absence of any thermodynamic data, the Gibbs energy of the transformation was assumed to be zero. That is, the parameters for this compound listed in Table 1 apply to both the phases.

Taylor $^{[38]}$ by XRD and thermal analysis, and Murray et al. ${ }^{[39]}$ by thermal analysis, reported the existence of a second phase close to $\mu-\mathrm{Al}_{4} \mathrm{Mn}$. Du et al. ${ }^{[5]}$ by XRD and differential thermal analysis (DTA) confirmed the presence of two distinct phases: $\mu-\mathrm{Al}_{4} \mathrm{Mn}$ at $X_{\mathrm{Mn}}=0.2$ and $\lambda-\mathrm{Al}_{4} \mathrm{Mn}$ at $X_{\mathrm{Mn}}=0.186$. They modeled the phase $\lambda-\mathrm{Al}_{4} \mathrm{Mn}$ as stoichiometric $\mathrm{Al}_{461} \mathrm{Mn}_{107}$ based on the crystallographic data of Kreiner and Franzen. ${ }^{[21]}$

Koch et al. ${ }^{[40]}$ studied the system by thermal analysis in the range $25-100$ at.\% Mn. Koster and Wachtel ${ }^{[41]}$ studied the system in the range $30-100$ at.\% Mn by thermal and magnetic analysis, microhardness, and XRD. Later, Godecke and Koster, ${ }^{[37]}$ by metallography and thermal 


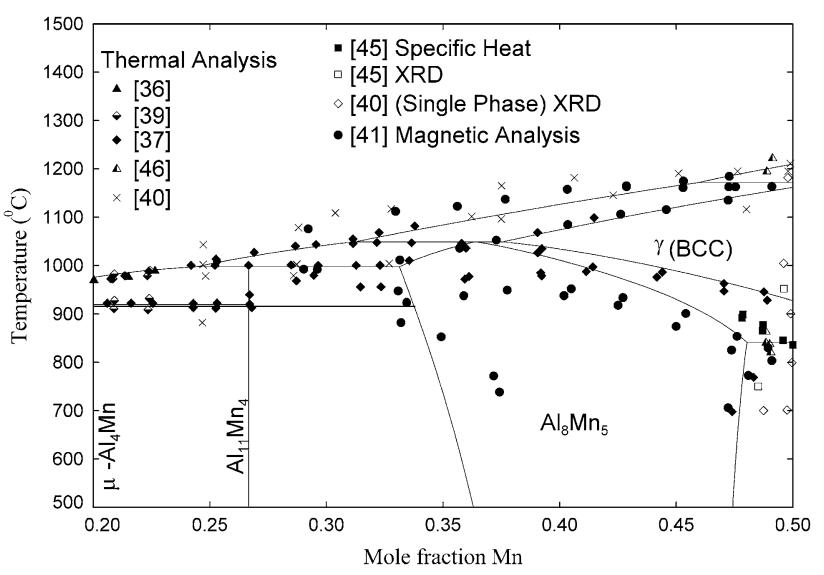

Fig. 4 Optimized phase diagram of the Al-Mn system for $0.2 \leq X_{\mathrm{Mn}} \leq 0.5$

analysis, reported three phases in the region from 30 to 50 at.\% Mn: $\gamma, \gamma 1$, and $\gamma 2$ (In Fig. 1, $\gamma$ is denoted $\gamma$ (BCC), while $\gamma 1$ and $\gamma 2$ are the $\mathrm{Al}_{8} \mathrm{Mn}_{5}$ phase). Ellner, ${ }^{[20]}$ using high temperature XRD, showed that the $\gamma$ phase has a BCC structure. As very little information is available about the $\gamma 1$ and $\gamma 2$ phases, they were modeled as a single phase " $\mathrm{Al}_{8} \mathrm{Mn}_{5}$ " (Fig. 1), as was also done in previous optimizations. $^{[4,5]}$. Following the suggestion, based on crystallographic data, ${ }^{[20]}$ of $\mathrm{Du}$ et al., ${ }^{[5]}$ the $\mathrm{Al}_{8} \mathrm{Mn}_{5}$ phase was modeled by the compound energy formalism ${ }^{[42,43]}$ as $\mathrm{Al}_{12} \mathrm{Mn}_{5}(\mathrm{Al}, \mathrm{Mn})_{9}$ (the first sublattice containing only $\mathrm{Al}$, the second only $\mathrm{Mn}$ and the third a random mixture of $\mathrm{Al}$ and $\mathrm{Mn}$ ).

The optimized phase diagram for the region from $0.2 \leq X_{\mathrm{Mn}} \leq 0.5$ is compared with experimental data in Fig. 4. In the absence of any further experimental evidence, the order-disorder transformation in the $\gamma$ (BCC) phase suggested by Liu et al. ${ }^{[4]}$ based upon preliminary differential scanning calorimetry (DSC) results ${ }^{[4]}$ was ignored. For modeling purpose, $\gamma$ (BCC) was formally treated as the same phase as the terminal $\mathrm{BCC}$ solid solution of $\mathrm{Al}$ and $\mathrm{Mn}$, but for clarity of representation, this region has been denoted as $\gamma$ (BCC) in the figures.

The optimized phase diagram in the region from $0.5 \leq X_{\mathrm{Mn}} \leq 0.1$ is compared with the experimental data in Fig. 5. The phase equilibria for the $\varepsilon$ (HCP) phase were first studied by XRD and specific heat measurements by Kono. ${ }^{[45]}$ Koster and Wachtel ${ }^{[41]}$ studied the boundaries of the phase by magnetic analysis, micro-hardness, XRD, and thermal analysis, and denoted the phase as $\varepsilon$. Muller et al. ${ }^{[46]}$ established phase equilibria for this phase by DTA. Liu et al. ${ }^{[24]}$ investigated the phase mainly by a diffusion couple technique, and also by metallography, XRD, DSC and transmission electron microscopy (TEM). They reported a wider single-phase region than Koster and Wachtel, ${ }^{[41]}$ attributing the difference to the transformation of $\varepsilon(\mathrm{HCP})$ at compositions richer in Mn than 58 at.\% into the CUB phase during the quenching experiments.

Meschel and Kleppa ${ }^{[47]}$ by direct synthesis calorimetry, reported the enthalpy of formation at $25{ }^{\circ} \mathrm{C}$ for alloys at 60

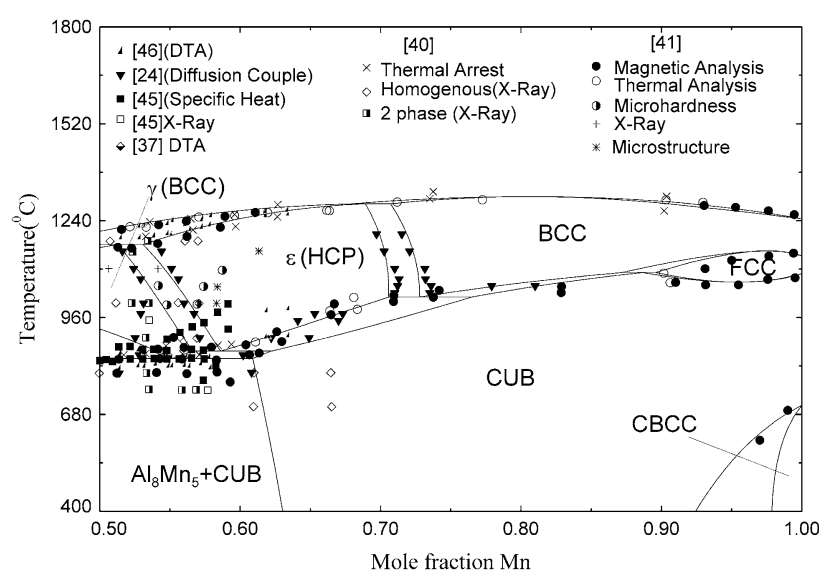

Fig. 5 Optimized phase diagram of the Al-Mn system for $0.5 \leq X_{\mathrm{Mn}} \leq 1.0$

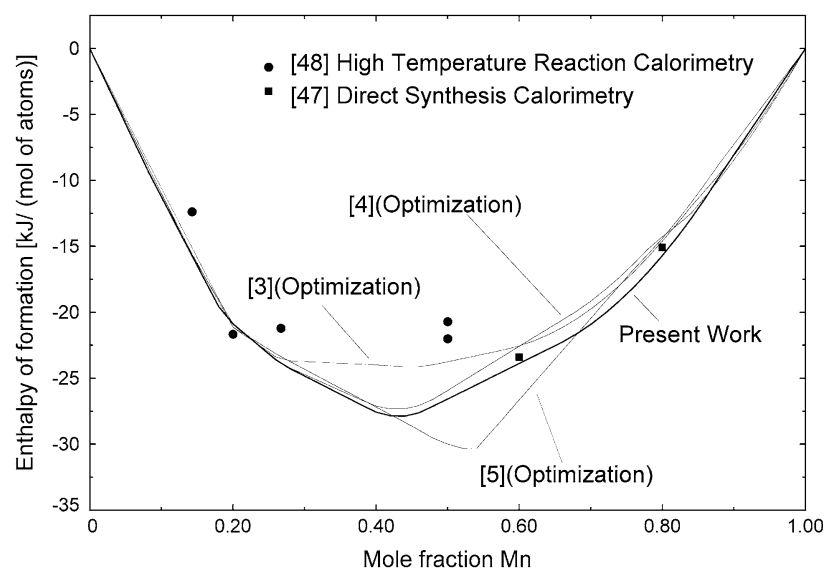

Fig. 6 Optimized standard enthalpies of formation of solid Al-Mn alloys

and 80 at.\% Mn. Kubaschewski and Heymer, ${ }^{[48]}$ by high temperature reaction calorimetery, reported enthalpies of formation for four compositions: $\mathrm{Al}_{6} \mathrm{Mn}, \mathrm{Al}_{4} \mathrm{Mn}, \mathrm{Al}_{11} \mathrm{Mn}_{4}$ and AlMn. The optimized standard enthalpy of formation of the intermediate compounds is compared with the experimental data and the previous optimizations in Fig. 6 .

Partial enthalpies of mixing in the liquid phase at $1353{ }^{\circ} \mathrm{C}$ were measured by high-temperature vacuum isothermal calorimetry by Esin et al. ${ }^{[6]}$ who reported only smoothed data. The present optimized enthalpy of mixing is compared with these data and with previous optimizations in Fig. 7.

Batalin et al. ${ }^{[49]}$ performed electromotive force (EMF) measurements in the liquid phase at $1297^{\circ} \mathrm{C}$, reporting activities of Mn, while Kematick and Myers ${ }^{[50]}$ measured Al and $\mathrm{Mn}$ activities at $902{ }^{\circ} \mathrm{C}$ by Knudsen cell/mass spectrometry in the range $42-62$ at.\% $\mathrm{Mn}$. These data are inconsistent with the other data for the system and were ignored. Chastel et al. ${ }^{[51]}$ determined activities of $\mathrm{Mn}$ and $\mathrm{Al}$ in the melt in the range from 0 to 50 at. $\% \mathrm{Mn}$ at $1247^{\circ} \mathrm{C}$ by Knudsen cell/mass spectrometry. The optimized activities 


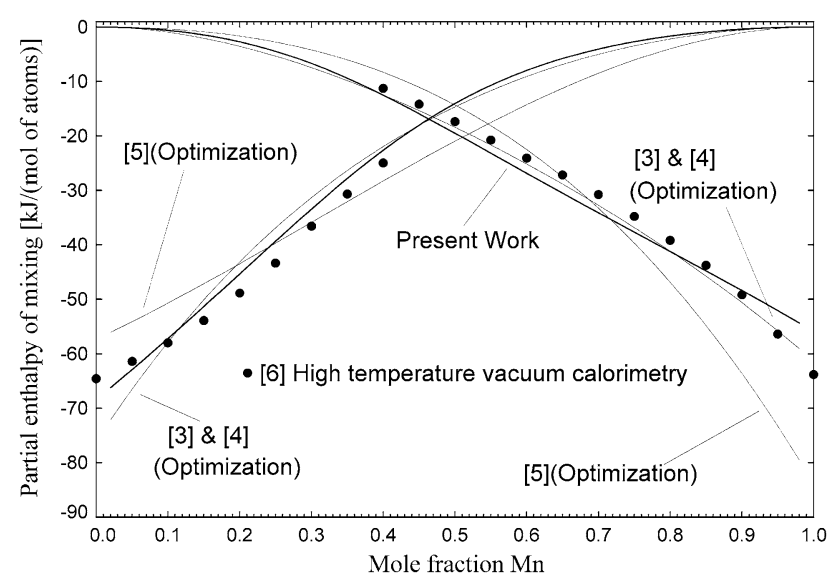

Fig. 7 Optimized partial enthalpies of mixing in liquid Al-Mn alloys at $1353{ }^{\circ} \mathrm{C}$

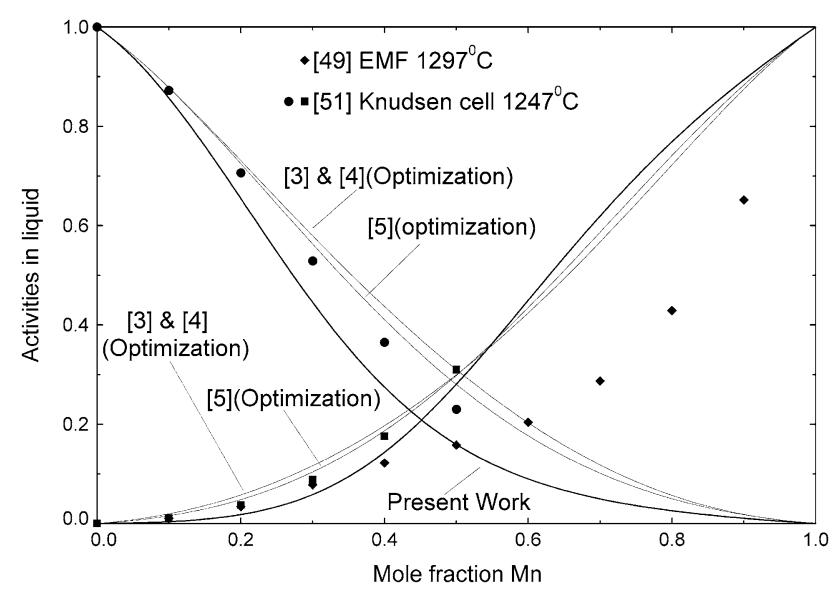

Fig. 8 Optimized activity of $\mathrm{Al}$ and $\mathrm{Mn}$ in liquid Al-Mn alloys at $1247^{\circ} \mathrm{C}$

are compared with the experimental data and previous optimizations in Fig. 8.

The optimized entropy of mixing in the liquid phase at $1400{ }^{\circ} \mathrm{C}$ is compared with the previous optimizations in Fig. 9. The present positive entropy of mixing is physically more probable than the negative values of the previous optimizations. The optimized standard entropies of formation of the solid alloys from the elements at $25{ }^{\circ} \mathrm{C}$ are compared with previous optimizations in Fig. 10 (see also Table 1). Generally, such entropies of formation are expected to be small, as in the case in the present study. It is not possible to obtain a closer fit to the liquid activity data in Fig. 8, simultaneously with all the other data for the system, without introducing a relatively large negative non-configurational entropy term for the liquid phase as well as significantly larger entropies of formation of the solid phases. Since such large entropies are physically improbable, we believe it to be more likely that the activity data are in error.

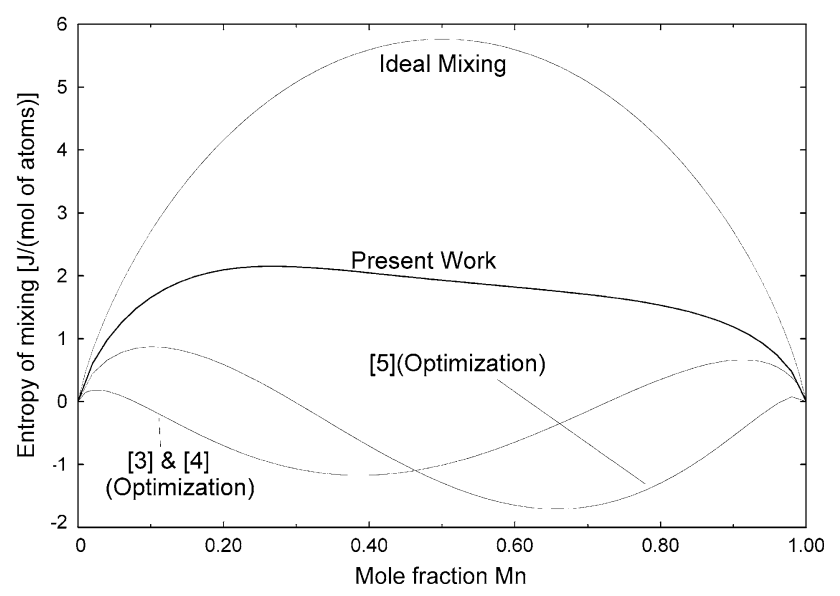

Fig. 9 Optimized entropy of mixing in liquid Al-Mn alloys at $1400{ }^{\circ} \mathrm{C}$

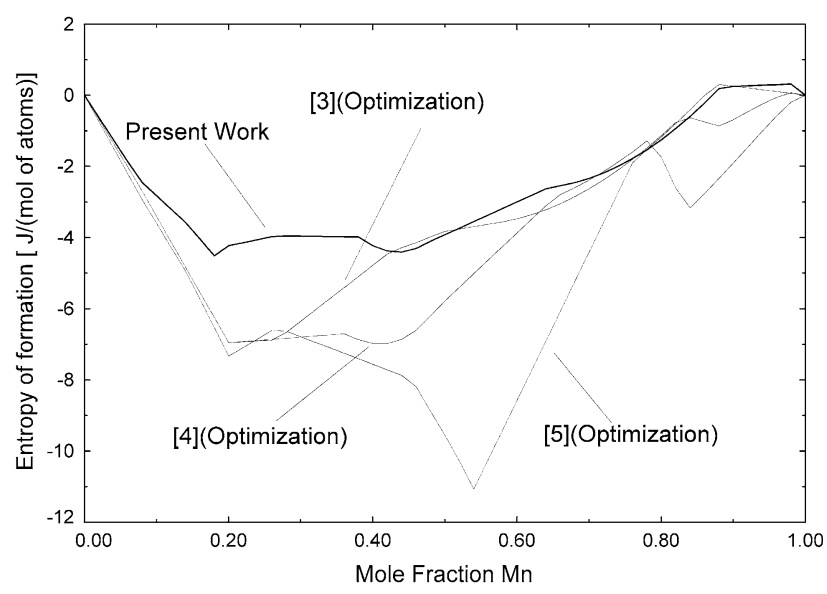

Fig. 10 Optimized standard entropies of formation at $25^{\circ} \mathrm{C}$ of solid Al-Mn alloys from the elements

\section{The Mg-Al-Mn System}

The previously optimized phase diagrams of the $\mathrm{Al}-\mathrm{Mg}^{[9]}$ and $\mathrm{Mg}-\mathrm{Mn}^{[10]}$ systems are shown in Fig. 11 and 12 respectively. The parameters optimized by Chartrand $^{[9]}$ for the phases in the Al-Mg system pertinent to the present work are given in Table 3. Crystallographic data of all the solid phases appearing in the Mg-Al-Mn system are in Table 2. It may be noted that the calculated consolute temperature of the miscibility gap in the $\mathrm{Mg}-\mathrm{Mn}$ system, Fig. 9 , is about $1500-2000{ }^{\circ} \mathrm{C}$ lower than in the previous optimizations ${ }^{[2,53]}$ of this binary system.

Our previous optimizations ${ }^{[9,10]}$ of the $\mathrm{Al}-\mathrm{Mg}$ and $\mathrm{Mg}-\mathrm{Mn}$ systems were combined with the present optimization of the Al-Mn system in order to calculate the polythermal projection of the liquidus of the Mg-Al-Mn system shown in Fig. 13. The thermodynamic properties of the ternary liquid phase were calculated by the MQM from the binary model 
parameters. The "asymmetric approximation" ${ }^{[18,54]}$ with Al as "asymmetric component" was used, since the Mg-Mn liquid exhibits positive deviations from ideality, whereas the $\mathrm{Al}-\mathrm{Mg}$ and Al-Mn liquids exhibit negative deviations. A small ternary interaction parameter (Table 1) was included for the liquid phase.

The HCP phase in the Al-Mg and Mg-Mn systems ${ }^{[9,10]}$ and the FCC phase in the Al-Mg system were modeled with single-sublattice substitutional models. For modeling

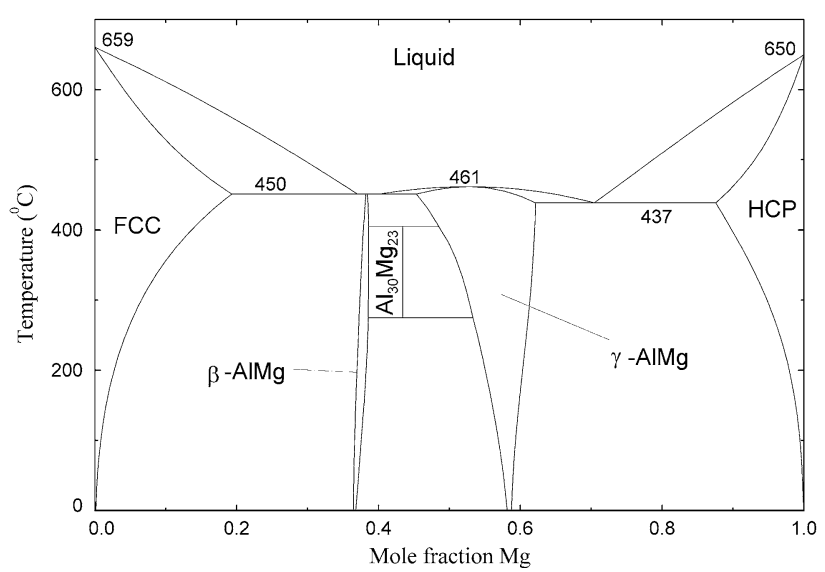

Fig. 11 Previously optimized phase diagram of the Al-Mg system $^{[9]}$

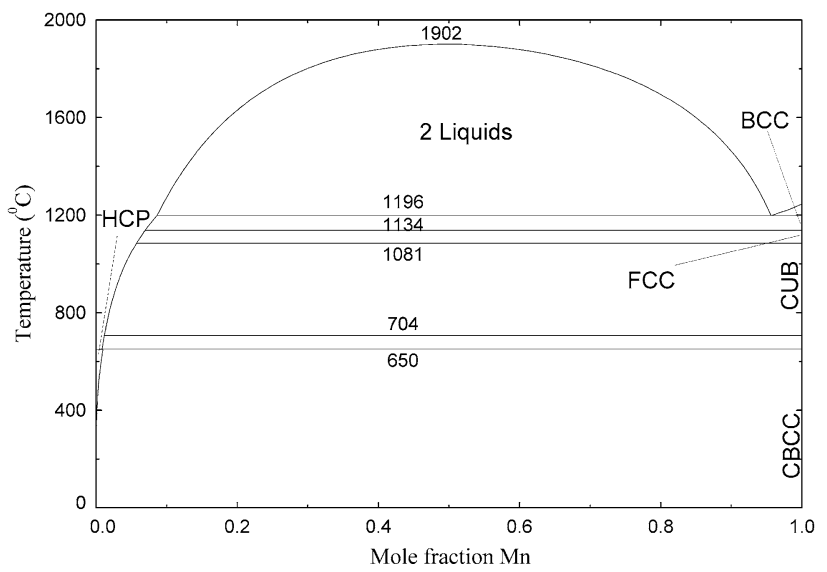

Fig. 12 Previously optimized phase diagram of the $\mathrm{Mg}-\mathrm{Mn}$ system $^{[10]}$ purposes, the Mg-rich HCP phase in the Al-Mg and Mg-Mn systems and the $\varepsilon$ (HCP) phase in the Al-Mn system were formally treated as the same phase. The thermodynamic properties of the ternary HCP and FCC phases were estimated from the binary model parameters. The "symmetric" (Kohler) approximation ${ }^{[54]}$ was used with no ternary interaction parameters. The predicted stability of the $\varepsilon$ (HCP) phase at $1200{ }^{\circ} \mathrm{C}$ is shown in Fig. 14 .

$\gamma$-AlMg has the same structure as the CBCC-Mn phase (Table 2). A small solubility of $\mathrm{Mn}$ in this compound or combined solubility of $\mathrm{Al}$ and $\mathrm{Mg}$ in CBCC-Mn might therefore be expected. No data for these solubilities could be found. Pending further experimental work, the binary phase $\gamma$-AlMg and CBCC-Mn were treated as separate phases. Possible mutual solubilities between any other intermetallic phases were assumed to be negligible in the absence of any experimental evidence and since they all have different structures and stoichiometries.

\subsection{Mg-Rich Alloys}

The solubilities of $\mathrm{Mn}$ in liquid $\mathrm{Mg}$ reported by Hanawalt et al. ${ }^{[5]}$ are significantly lower than later findings ${ }^{[56,57]}$ and have been rejected. Beerwald ${ }^{[56]}$ and Nelson ${ }^{[57]}$ used a settling technique to determine solubilities. Oberländer et al., ${ }^{[58]}$ and later Simensen et al. ${ }^{[59]}$ from the same

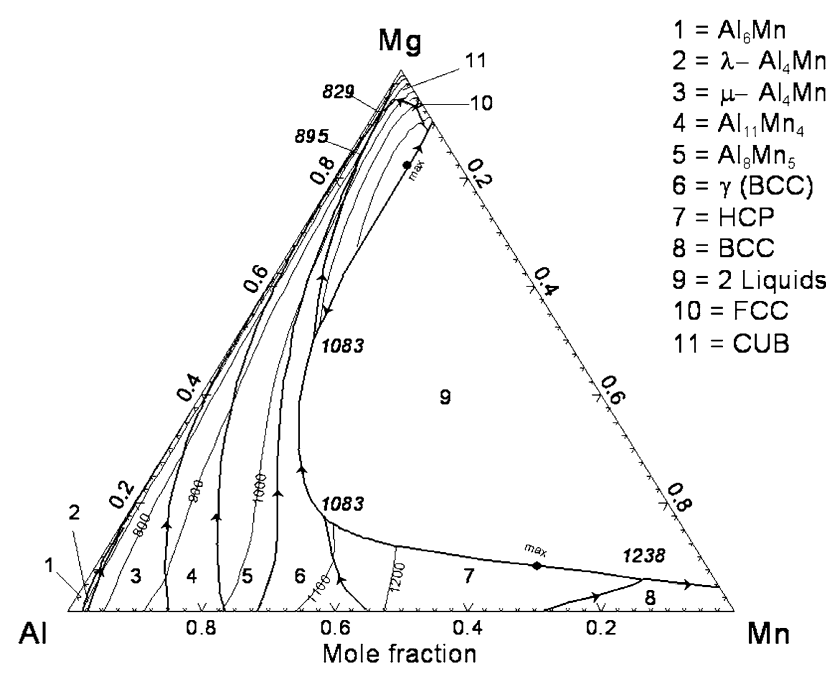

Fig. 13 Predicted polythermal projection of the liquidus in the $\mathrm{Mg}-\mathrm{Al}-\mathrm{Mn}$ system. Calculated invariant temperatures are shown $\left({ }^{\circ} \mathrm{C}\right)$

Table 3 Optimized parameters from Chartrand ${ }^{[9]}$ for phases in the Al-Mg system pertinent to the present work

\begin{tabular}{|c|c|}
\hline Phases (model used) & Optimized parameters, $\mathrm{J}$ \\
\hline Liquid (MQM) & $\begin{array}{l}\Delta g_{\mathrm{Al}-\mathrm{Mn}}=(-2762+1.527 T)+(-418+0.628 T) X_{\mathrm{Al}-\mathrm{Al}} \\
\text { Coordination numbers: } Z_{\mathrm{MgMg}}^{\mathrm{Mg}}=Z_{\mathrm{AlAl}}^{\mathrm{Al}}=Z_{\mathrm{AlMg}}^{\mathrm{Al}}=Z_{\mathrm{MgAl}}^{\mathrm{Mg}}=6\end{array}$ \\
\hline Solid solutions & Excess Gibbs energy terms, $G^{\mathrm{E}} / X_{\mathrm{Mg}} X_{\mathrm{Al}}(\mathrm{J} / \mathrm{mol}$ of atoms $)$ \\
\hline FCC (single-sublattice random mixing) & $(4971-3.500 T)+(-900-0.423 T)\left(X_{\mathrm{Mg}}-X_{\mathrm{Al}}\right)$ \\
\hline HCP (single-sublattice random mixing) & $(1950-1.999 T)+(-1480+2.079 T)\left(X_{\mathrm{Mg}}-X_{\mathrm{Al}}\right)+3500\left(X_{\mathrm{Mg}}-X_{\mathrm{Al}}\right)^{2}$ \\
\hline
\end{tabular}




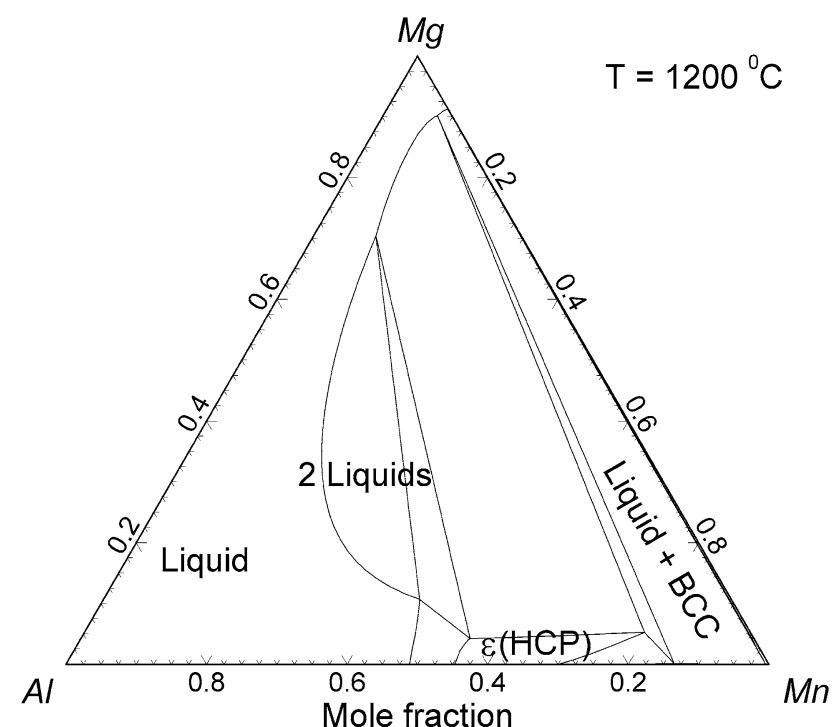

Fig. 14 Calculated isothermal section of the Mg-Al-Mn phase diagram at $1200{ }^{\circ} \mathrm{C}$

laboratory, identified the composition of precipitated solids around $700-750{ }^{\circ} \mathrm{C}$ by a centrifuging technique supplemented with XRD and metallography. They concluded that at $700-750{ }^{\circ} \mathrm{C}, \mathrm{CUB}$ and $\mathrm{Al}_{8} \mathrm{Mn}_{5}$ are the equilibrium phases at compositions $0 \leq \mathrm{wt} . \% \mathrm{Mn} \leq 3$ and $0 \leq \mathrm{wt} . \% \mathrm{Al} \leq 15$. The present calculations agree well with these data. In another work, Simensen et al., ${ }^{[60]}$ reported solubilities at 750,710 and $670{ }^{\circ} \mathrm{C}$ by the same technique. Thorvaldsen and Aliravci ${ }^{[61]}$ measured the solubility of $\mathrm{Mn}$ in the liquid phase by settling and decantation followed by emission spectrometry and inductively coupled plasma (ICP) measurements.

The data of Nelson, ${ }^{[57]}$ Beerwald, ${ }^{[56]}$ Simensen et al. ${ }^{[60]}$ and Thorvaldsen and Aliravci ${ }^{[61]}$ are compared with the present calculations in Fig. 15. All data except those of Simensen et al. ${ }^{[60]}$ are reasonably well reproduced below $780{ }^{\circ} \mathrm{C}$. The solubilities reported by Simensen et al. ${ }^{[60]}$ are lower than the present calculations and the disagreement increases with increasing temperature. This same trend was noted by Ohno and Schmid-Fetzer ${ }^{[62]}$ in their assessment. Thorvaldsen and Aliravci ${ }^{[61]}$ reported that the results of Simensen et al. $^{[60]}$ may have been influenced by iron contamination. A calculated isopleth at $5.05 \mathrm{wt} . \% \mathrm{Al}$ is compared with the data of Thorvaldsen and Aliravci ${ }^{[61]}$ in Fig. 16.

Mirgalovskaya et al., ${ }^{[63]}$ by microstructural and microhardness tests, studied liquid-solid and solid-solid phase equilibria in Mg-rich alloys. Their data are compared with the present calculations in Fig. 17. Their results at $850{ }^{\circ} \mathrm{C}$ are inconsistent with the measurements of other authors as can be seen by comparing Fig. 17(b) and 15(c). Other measurements of Mirgalovskaya et al. ${ }^{[63]}$ and Ageev et al. ${ }^{[64]}$ in Mg-rich alloys at temperatures below $400{ }^{\circ} \mathrm{C}$ were rejected because they report large solubilities of $\mathrm{Mn}$ and $\mathrm{Al}$ in $\mathrm{Mg}$ which are inconsistent with the other data.

The solidus measurements of Nelson ${ }^{[57]}$ are compared with the calculations in Fig. 18. The disagreement is due to
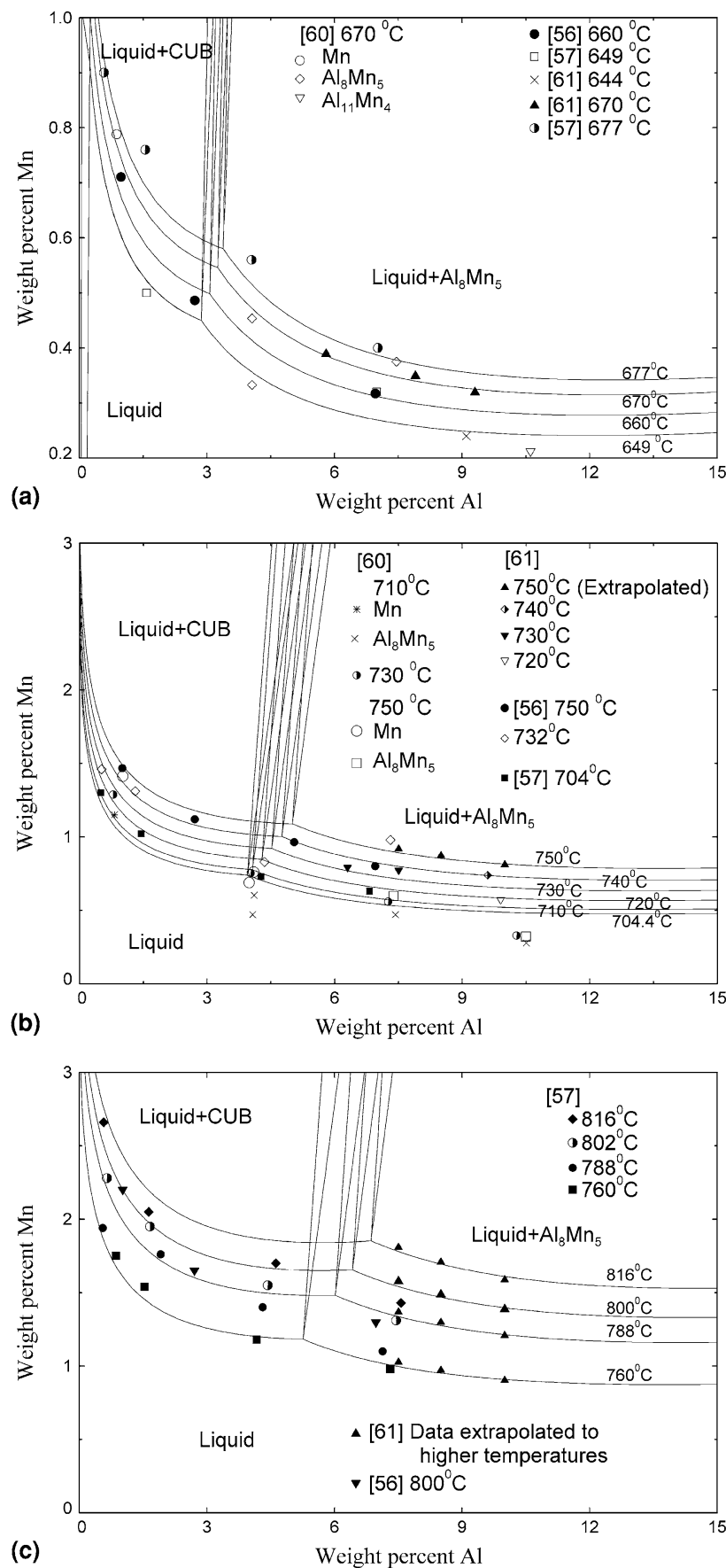

Fig. 15 Optimized liquidus surface in Mg-rich solutions at different temperatures $T$ : (a) $T<700{ }^{\circ} \mathrm{C}$, (b) $700<T \leq 750{ }^{\circ} \mathrm{C}$, and (c) $T>750{ }^{\circ} \mathrm{C}$

the fact that these measurements are inconsistent with other data in the binary Al-Mg system (wt.\% $\mathrm{Mn}=0$ in Fig. 18) which were used in the optimization of this binary system.

In the present work, for all practical purposes the solubility data up to $760{ }^{\circ} \mathrm{C}$ can be reproduced without any ternary interaction parameters. The small ternary term shown in Table 1 is only required to refine the optimization at the higher temperatures. 


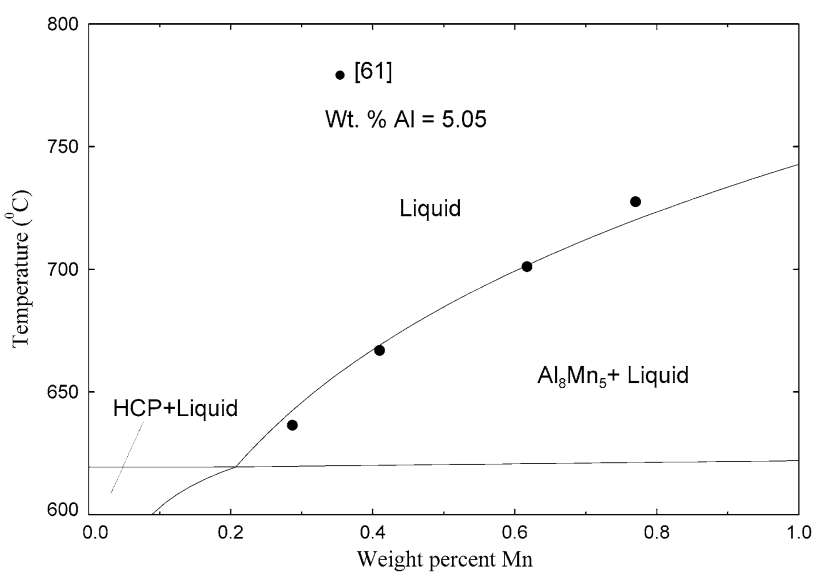

Fig. 16 Calculated section of the Mg-Al-Mn phase diagram at constant 5.05 wt. $\%$ Al
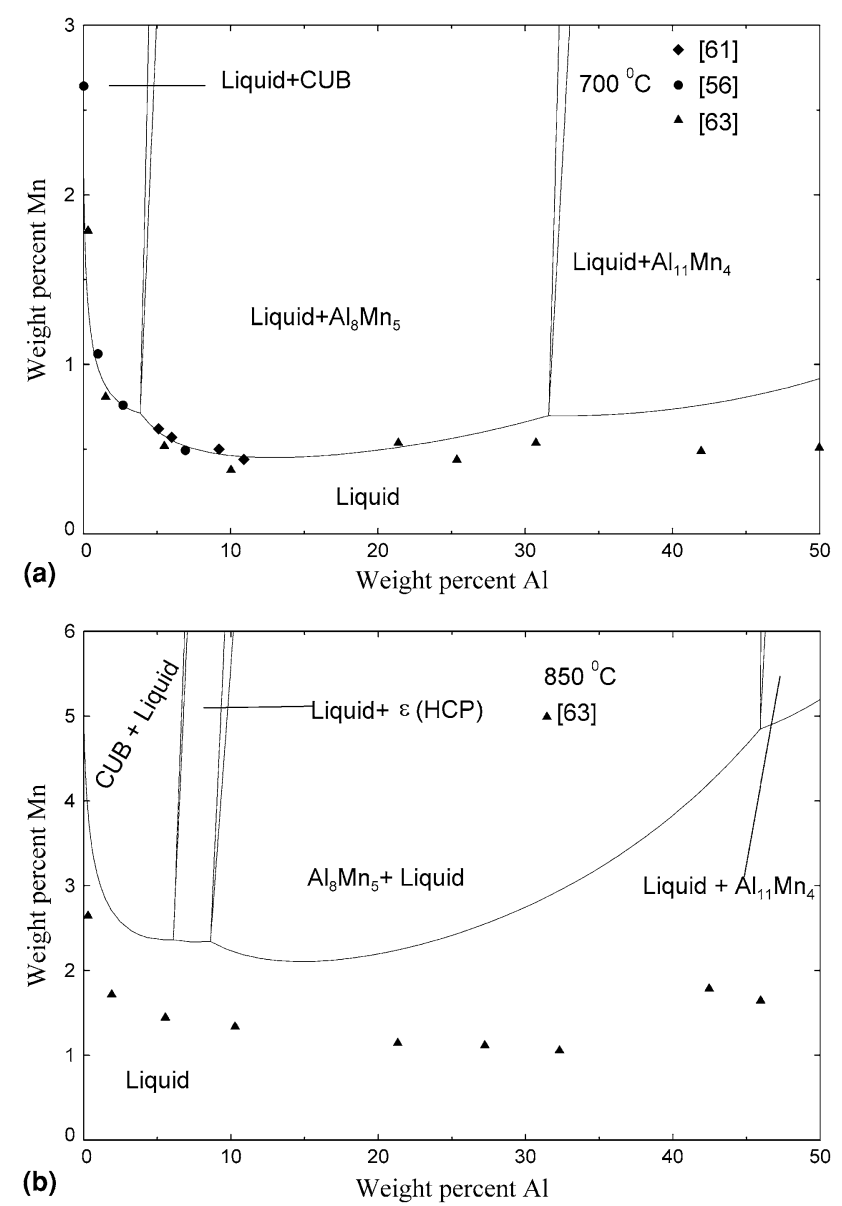

Fig. 17 Calculated liquidus surface in the $\mathrm{Mg}-\mathrm{Al}-\mathrm{Mn}$ system: (a) $700{ }^{\circ} \mathrm{C}$ and (b) $850{ }^{\circ} \mathrm{C}$

\subsection{Al-Rich Alloys}

Leemann and Hanemann ${ }^{[65]}$ studied Al-rich alloys by metallography and thermal analysis. Wakeman and

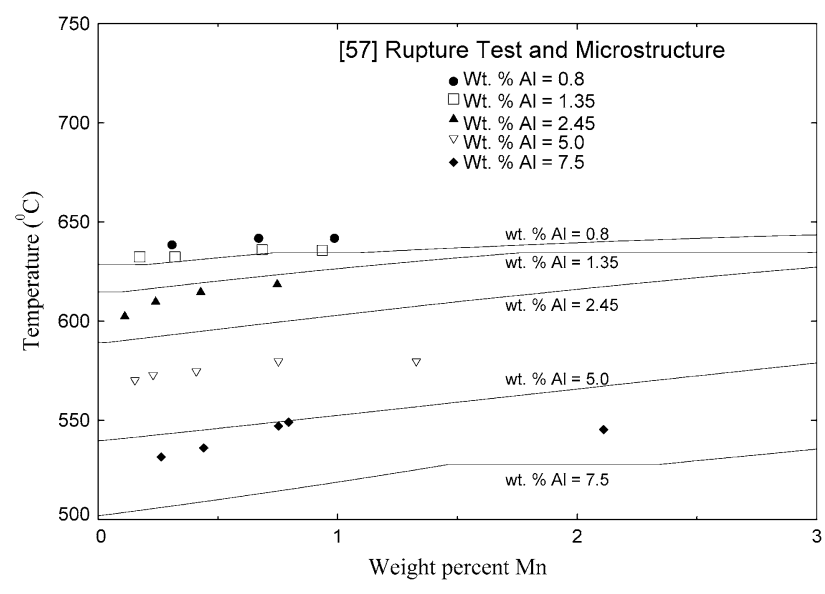

Fig. 18 Calculated solidus curves in the Mg-Al-Mn system

Raynor $^{[66]}$ doubted the attainment of equilibrium in Leemann and Hanemann's work ${ }^{[65]}$ and carried out microstructural observations of alloys annealed at $400{ }^{\circ} \mathrm{C}$. These authors ${ }^{[66]}$ reported a ternary compound by XRD and tentatively reported its composition to be $\mathrm{MnMg}_{2} \mathrm{Al}_{10}$. Later, Fun et al. ${ }^{[67]}$ determined the crystal structure of this phase by XRD and reported its composition to be $\mathrm{Mn}_{2} \mathrm{Mg}_{3} \mathrm{Al}_{18}$. This phase is denoted as $\mathbf{T}$ in the present work. Du et al. ${ }^{[5]}$ reported the enthalpy of formation of $\mathbf{T}$ as $-10.2 \mathrm{~kJ} /(\mathrm{mol}$ of atoms) by first principles calculations and as $-8.7 \mathrm{~kJ} /(\mathrm{mol}$ of atoms) by a CALPHAD-type assessment. The present optimization gives the enthalpy of formation as $-9.9 \mathrm{~kJ} /(\mathrm{mol}$ of atoms).

Barlock and Mondolfo ${ }^{[68]}$ reported a eutectic invariant reaction $\mathrm{L}=(\mathrm{Al})+\beta-\mathrm{AlMg}+\mathbf{T}$ at $447^{\circ} \mathrm{C}$. The present computed temperature for this reaction is $451{ }^{\circ} \mathrm{C}$. According to the present calculations, the $\mathbf{T}$ phase should melt peritectically near $471{ }^{\circ} \mathrm{C}$. The primary crystallization field for this ternary phase is extremely small and is very close to the $\mathrm{Mg}-\mathrm{Al}$ binary edge of the composition triangle. It is not visible on the scale of Fig. 13.

Ohnishi et al. ${ }^{[69]}$ studied Al-rich alloys at 400 and $450{ }^{\circ} \mathrm{C}$ by metallography and XRD. Isothermal sections at 400 and $450{ }^{\circ} \mathrm{C}$ are compared with the experimental data in Fig. 19 and 20. Ohnishi et al. ${ }^{[69]}$ also reported two-phase $\left(\mathrm{FCC}+\mathrm{Al}_{6} \mathrm{Mn}\right)$ regions (not shown here) at very low $\mathrm{Mg}$ and $\mathrm{Mn}$ contents at 400 and $450{ }^{\circ} \mathrm{C}$ which are inconsistent with the optimized Al-Mn binary phase diagram. In a different work, Ohnishi et al. ${ }^{[70]}$ studied six Al-rich alloys, showing the two-phase $\mathrm{FCC}+\mathrm{Al}_{6} \mathrm{Mn}$ region to be stable for $1 \leq \mathrm{wt} . \% \mathrm{Mn} \leq 2$ and $0 \leq \mathrm{wt} . \% \mathrm{Mg} \leq 4$, in agreement with the present calculations.

Butchers et al., ${ }^{[71]}$ from cooling curves, reported smoothed liquidus curves between 630 and $650{ }^{\circ} \mathrm{C}$. The data at $650{ }^{\circ} \mathrm{C}$ are compared with the present calculations in Fig. 20.

Little et al. ${ }^{[72]}$ by microstructure observations, and Fahrenhorst and Hoffman ${ }^{[25]}$ by electrical resistance measurements, reported solubilities of $\mathrm{Mn}$ and $\mathrm{Mg}$ at $500{ }^{\circ} \mathrm{C}$ in the FCC phase. These data are compared with the present calculations in Fig. 21. 


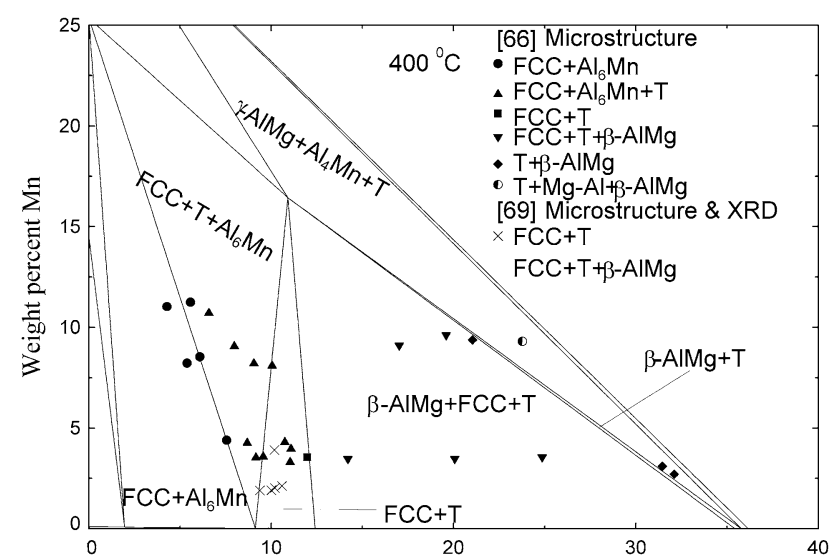

(a)

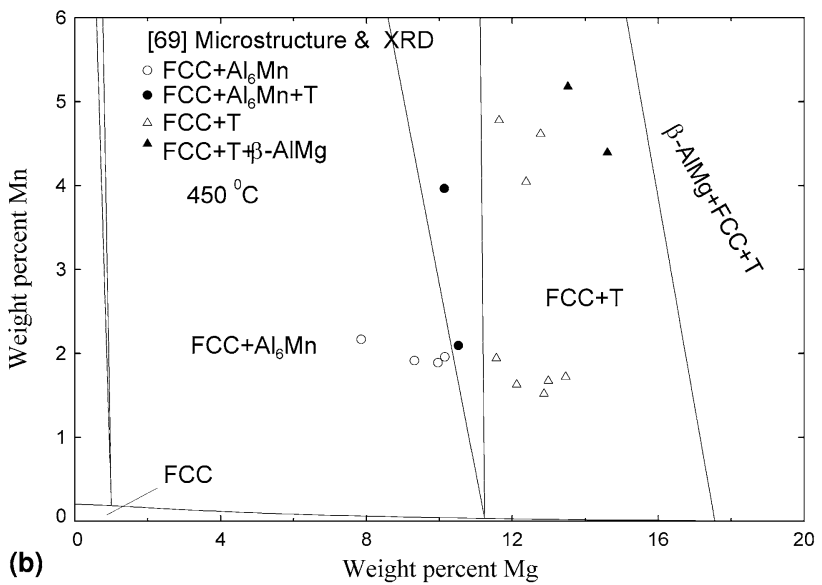

Fig. 19 Calculated isothermal sections of the Mg-Al-Mn phase diagram: (a) $400{ }^{\circ} \mathrm{C}$ and (b) $450{ }^{\circ} \mathrm{C}$

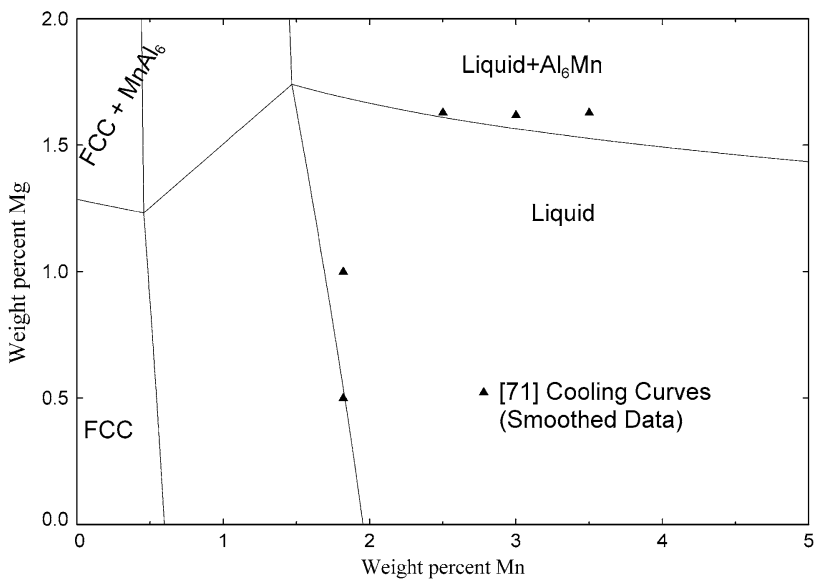

Fig. 20 Calculated liquidus surface in the Mg-Al-Mn system

\section{Conclusions}

Gibbs energy functions for all phases in the Al-Mn system have been obtained. All available thermodynamic

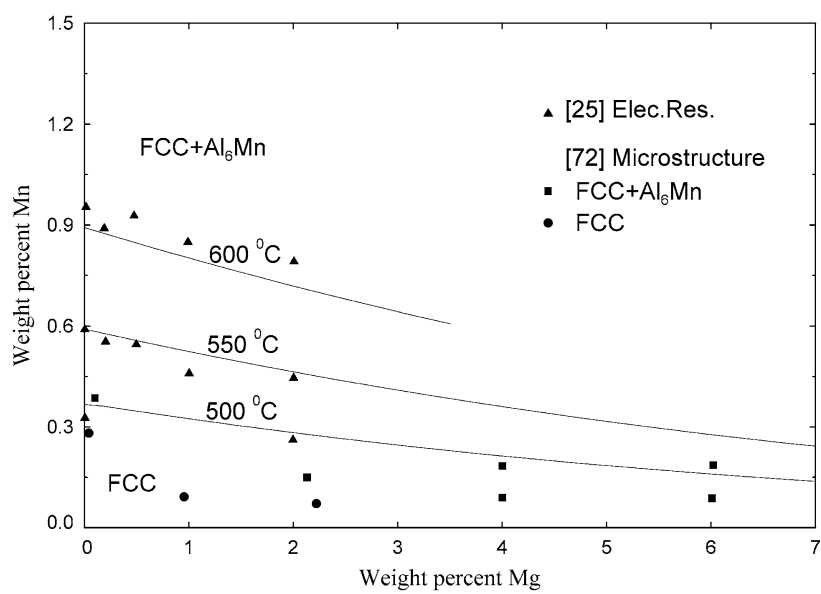

Fig. 21 Calculated solubility of $\mathrm{Mn}$ and $\mathrm{Mg}$ in FCC-Al

and phase equilibrium data have been critically evaluated in order to obtain one set of optimized model parameters of the Gibbs energies of all phases which can reproduce the experimental data within experimental error limits. Tentative calculated phase diagrams of the Mg-Al-Mn system have been given. For all practical purposes, the available data below $760{ }^{\circ} \mathrm{C}$ in the Mg-Al-Mn system can be reproduced solely from the optimized binary model parameters. A small ternary parameter has been included for the liquid phase to refine the optimization at higher temperatures.

The use of the MQM for the liquid phase has permitted SRO to be taken into account. Use of this model results in a better fitting of the data for the liquid phase than is the case when a Bragg-Williams random-mixing model is used, as well as a better representations of the partial properties of solutes in dilute solution in magnesium, the activities of solutes in dilute solution being of much practical importance. As shown by the present authors, ${ }^{[7]}$ the use of the MQM generally also results in better estimations of the properties of ternary and higher-order liquid alloys. These estimations of phase equilibria in magnesium alloys will aid in the design of novel magnesium alloys.

\section{Acknowledgments}

Financial support from General Motors of Canada Ltd. and the Natural Sciences and Engineering Research Council of Canada through the CRD grants program is gratefully acknowledged.

\section{References}

1. C.W. Bale, P. Chartrand, S.A. Degterov, G. Eriksson, K. Hack, R. Ben Mahfoud, J. Melançon, A.D. Pelton, and S. Petersen, FactSage Thermochemical Software and Databases, CALPHAD, 2002, 26(2), p 189-228

2. C.W. Bale, A.D. Pelton, and W. Thompson, FactSage Thermochemcial Software and Databases, http://www.crct. polymtl.ca (2008) 
3. A. Jansson, Thermodynamic Evaluation of the Al-Mn System, Metall. Mater. Trans. A, 1992, 23A, p 2953-2962

4. X.J. Liu, I. Ohnuma, R. Kalnuma, and K. Ishida, Thermodynamic Assessment of the Al-Mn Binary Phase Diagram, J. Phase Equilib., 1999, 20(1), p 45-56

5. Y. Du, J. Wang, J. Zhao, J.C. Schuster, F. Weitzer, R. Schmid-Fetzer, M. Ohno, H. Xu, Z. Liu, S. Shang, and W. Zhang, Reassessment of the Al-Mn System and a Thermodynamic Description of the Al-Mg-Mn System, Int. J. Mater. Res., 2007, 98, p 855-871

6. Y.O. Esin, N.T. Bobrov, M.S. Petrushevskii, and P.V. Geld, Concentration Variation of the Enthalpies of Formation of Mn-Al Melts at 1626 K, Russ. J. Phys. Chem., 1973, 47, p 1103-1105

7. A.D. Pelton and Y.-B. Kang, Modeling Short-Range Ordering in Solutions, Int. J. Mater. Res., 2007, 10, p 907-917

8. A.D. Pelton, S.A. Degterov, G. Eriksson, C. Robelin, and Y. Dessureault, The Modified Quasichemical Model I - Binary Solutions, Metall. Mater. Trans. B, 2000, 31B(6), p 651-659

9. P. Chartrand, CRCT, Ecole Polytechnique, Montreal, 2006 (unpublished work)

10. Y.-B. Kang, A.D. Pelton, P. Chartrand, P. Spencer, and C.D. Fuerst, Critical Evaluation and Thermodynamic Optimization of the Binary Systems in the Mg-Ce-Mn-Y System, J. Phase Equilib. Diffus., 2007, 28(4), p 342-354

11. P. Chartrand and A.D. Pelton, Thermodynamic Evaluation and Optimization of the LiCl-NaCl-KCl-RbCl-CsCl- $\mathrm{MgCl}_{2}-\mathrm{CaCl}_{2}$ System Using the Modified Quasichemical Model, Metall. Mater. Trans. A, 2001, 32A(6), p 1361-1383

12. P. Chartrand and A.D. Pelton, Thermodynamic Evaluation and Optimization of the LiF-NaF-KF-MgF $-\mathrm{CaF}_{2}$ System Using the Modified Quasichemical Model, Metall. Mater. Trans. A, 2001, 32A(6), p 1385-1396

13. P. Chartrand and A.D. Pelton, Thermodynamic Evaluation and Optimization of the $\mathrm{Li}, \mathrm{Na}, \mathrm{K}, \mathrm{Mg}, \mathrm{Ca} / / \mathrm{F}, \mathrm{Cl}$ Reciprocal System Using the Modified Quasichemical Model, Metall. Mater. Trans. A, 2001, 32A(6), p 1417-1430

14. S.A. Decterov, I.-H. Jung, E. Jak, Y.-B. Kang, P. Hayes, and A.D. Pelton, Thermodynamic Modelling of the $\mathrm{Al}_{2} \mathrm{O}_{3}-\mathrm{CaO}-$ $\mathrm{CoO}-\mathrm{CrO}-\mathrm{Cr}_{2} \mathrm{O}_{3}-\mathrm{FeO}-\mathrm{Fe}_{2} \mathrm{O}_{3}-\mathrm{MgO}-\mathrm{MnO}-\mathrm{NiO}-\mathrm{SiO}_{2}-\mathrm{S}$ System and Application in Ferrous Process Metallurgy, Proceedings of the VII International Conference on Molten Slags, Fluxes and Salts, C. Pistorius, Ed. (Johannesburg, South Africa), The South African Institute of Mining and Metallurgy, 2004, p $839-850$

15. P. Waldner and A.D. Pelton, Thermodynamic Modeling of the Ni-S System, Z. Metallkd., 2004, 95, p 672-681

16. P. Waldner and A.D. Pelton, Critical Thermodynamic Assessment and Modeling of the Fe-Ni-S System, Metall. Mater. Trans. B, 2004, 35B(5), p 897-907

17. P. Waldner and A.D. Pelton, Thermodynamic Modeling of the Fe-S System, J. Phase Equilib. Diffus., 2005, 26(1), p 23-38

18. A.D. Pelton and P. Chartrand, The Modified Quasichemical Model: Part II. Multicomponent Solutions, Metall. Mater. Trans. A, 2001, 32A(6), p 1355-1360

19. A.T. Dinsdale, SGTE Data for Pure Elements, CALPHAD, 1991, 15(4), p 317-425 plus updates (private communication), 2000, http://www.sgte.org

20. M. Ellner, The Structure of the High-Temperature Phase MnAl (h) and the Displacive Transformation from MnAl (h) into $\mathrm{Mn}_{5} \mathrm{Al}_{8}$, Metall. Mater. Trans. A, 1990, 21A, p 1669-1672

21. G. Kreiner and H.F. Franzen, The Crystal Structure of $\lambda$-Al ${ }_{4} \mathrm{Mn}, J$. Alloys Compd., 1997, 261, p 83-104

22. P. Villars and L.D. Calvert, Pearson's Handbook of Crystallographic Data for Intermetallic Phases, ASM, Materials Park, OH, 1991
23. A.J. McAlister and J.L. Murry, The Al-Mn System, Bull. Alloy Phase Diagrams, 1987, 8(5), p 438-446

24. X.J. Liu, I. Ohnuma, R. Kalnuma, and K. Ishida, Phase Equilibria in the Mn-Rich Portion of the Binary System Mn-A1, J. Alloys Compd., 1996, 235, p 256-261

25. E. Fahrenhorst and W. Hoffman, The Solubility of Manganese in Aluminum Containing up to 2 Percent of Magnesium, Metallwirtschaft, 1940, 19, p 891-893

26. E. Butchers and W. Hume-Rothery, The Solubility of Manganese in Aluminum, J. Inst. Met., 1945, 71, p 87-91

27. I. Obinata, E. Hata, and K. Yamaji, Chiefly on the Sub-Cooled Al-Mn Alloys, J. Inst. Met., 1953, 17, p 496-501

28. G.M. Kuznetsov, A.D. Barsukov, and M.I. Abas, Study of Manganese, Chromium, Titanium, and Zirconium Solubility in Solid Aluminum, Sov. Non Ferrous Met. Res., 1983, 11, p 4751

29. Y. Minamino, T. Yamane, H. Araki, N. Takeuchi, Y.-S. Kang, Y. Miyamoto, and T. Okamoto, Solid Solubilities of Mn and Ti in Aluminum at $0.1 \mathrm{MPa}$ and $2.1 \mathrm{GPa}$, Metall. Mater. Trans. $A, 1991,22$ A, p 783-786

30. V.A. Livanov and V.M. Vozdvizhenskii, Recrystallization of Aluminum Alloys with Manganese, Trudy Moskov. Aviatsion, Tekhnol. Inst., 1958, 31, p 65-83

31. E.H. Dix and W.D. Keith, Equilibrium Relations in Al-Mn Alloys of High Purity, Proc. AIME, Inst. Metals Div., 1927, p 315-335

32. M.E. Drits, E.S. Kadaner, E.M. Padzhnova, and N.R. Bochvar, Determination of the Boundaries of Common Solubility of Mn and Cd in Solid Aluminum, Zh. Neorg. Khim., 1964, 9(6), p $1397-1402$

33. C. Sigli, CALPHAD XXIV Conference, Kyoto, Japan, 1995, quoted by Du et al. [5]

34. E.H. Dix, W.L. Fink, and L.A. Willey, Equilibrium Relations in Al-Mn Alloys of High Purity II, Trans. AIME, 1933, 104, p 335-352

35. R.J. Schaefer, F.S. Biancaniello, and J.W. Cahn, Formation and Stability Range of the G Phase in the Al-Mn System, Scr. Metall., 1986, 20(10), p 1439-1444

36. H.W.L. Phillips, The Constitution of Alloys of Aluminium with Manganese Silicon and Iron, J. Inst. Met., 1942, 69, p $275-316$

37. T. Godecke and W. Koster, A Supplement to the Constitution of the Al-Mn System, Z. Metallkd., 1971, 62(10), p 727-732

38. M.A. Taylor, Intermetallic Phases in the Al-Mn Binary System, Acta Metall., 1960, 8, p 256-262

39. J.L. Murray, A.J. McAlister, R.J. Schaefer, L.A. Bendersky, F.S. Biancaniella, and D.L. Moffatt, Stable and Metastable Phase Equilibria in the Al-Mn System, Metall. Trans. A, 1987, 18A, p 385-392

40. A.J.J. Koch, P. Hokkeling, M.G.V.D. Steeg, and K.J. Devos, New Material for Permanent Magnets on a Base of $\mathrm{Mn}$ and $\mathrm{Al}$, J. Appl. Phys., 1960, 31(5), p 75S-77S

41. W. Koster and E. Wachtel, Magnetic Investigation of Al-Mn Alloys Containing More Than 25 at. \% Mn, Z. Metallkd., 1960, 51, p 271-280

42. M. Hillert and L.-I. Staffansson, Regular Solution Model for Stoichiometric Phases and Ionic Melts, Acta Chem. Scand., 1970, 24(10), p 3618-3626

43. J.O. Andersson, A.F. Guillermet, M. Hillert, B. Jansson, and B. Sundman, A Compound-Energy Model of Ordering in a Phase with Sites of Different Coordination Numbers, Acta Metall., 1986, 34(3), p 437-445

44. X.J. Liu, Ph.D. Thesis, Tohoku University, Japan, 1998

45. H. Kono, On the Ferromagnetic Phase in Mn-Al System, J. Phys. Soc. Jpn., 1958, 13, p 1444-1451 
46. C. Muller, H. Stadelmaier, B. Reinsch, and G. Petzow, Metallurgy of the Magnetic $\tau$-Phase in $\mathrm{Mn}-\mathrm{Al}$ and Mn-Al-C, Z. Metallkd., 1996, 87(7), p 594-597

47. S.V. Meschel and O.J. Kleppa, The Standard Enthalpies of Formation of Some 3d Transition Metal Aluminides by HighTemperature Direct Synthesis Calorimetery, NATO ASI Series, Ser. E, 1994, 256, p 103-112

48. O. Kubaschewski and G. Heymer, Heats of Formation of Transition-Metal Aluminides, Trans. Faraday Soc., 1960, 56, p 473-478

49. G.I. Batalin, E.A. Beloborodova, V.A. Stukalo, and A.A. Chekhovskii, Thermodynamic Properties of Molten Alloys of Aluminum with Manganese, Ukr. Khim. Zh., 1972, 38(8), p 825-827

50. R.J. Kematick and C.E. Myers, Thermodynamics and Phase Equilibria in the Al-Mn System, J. Alloys Compd., 1992, 178, p 343-349

51. R. Chastel, M. Saito, and C. Bergman, Thermodynamic Investigation on $\mathrm{Al}_{1-\mathrm{x}} \mathrm{Mn}_{\mathrm{x}}$ Melts by Knudsen Cell Mass Spectrometry, J. Alloys Compd., 1994, 205, p 39

52. J. Tibbals, Mg-Mn System, COST 507 - Thermochemical Databases for Light Metal Alloys, I. Ansara, A.T. Dinsdale, and M.H. Rand, Eds., Vol. 2, EUR 18499, 1998, p 215-217

53. J. Gröbner, D. Mirkovic, M. Ohno, and R. Schmid-Fetzer, Experimental Investigation and Thermodynamic Calculation of Binary Mg-Mn Phase Equilibria, J. Phase Equilib. Diffus., 2005, 26(3), p 234-239

54. A.D. Pelton, A General "Geometric" Thermodynamic Model for Multicomponent Solutions, CALPHAD, 2001, 25(2), p 319-328

55. J.D. Hanawalt, C.E. Nelson, and G.E. Holdeman, Removal of Iron from Mg-Base Alloys, US Patent No. 2267862, December 30,1941

56. A. Beerwald, On the Solubility of Iron and Manganese in Magnesium and in Magnesium-Aluminium Alloys, Metallwirtschaft, 1944, 23, p 404-407

57. B.J. Nelson, Equilibrium Relations in Mg-Al-Mn Alloys, J. Met., 1951, 3, p 797-799

58. B.C. Oberländer, C.J. Simensen, J. Svalestuen, and A. Thorvaldsen, Phase Diagram of Liquid Magnesium-AluminiumManganese Alloys, Magnesium Technology, Pros. Conf., London, 1986, p 133-137

59. C.J. Simensen, B.C. Oberländer, J. Svalestuen, and A. Thorvaldsen, Determination of the Equilibrium Phases in Molten Mg-4 wt. \% Al-Mn Alloys, Z. Metallkd., 1988, 79, p $537-540$
60. C.J. Simensen, B.C. Oberländer, J. Svalestuen, and A. Thorvaldsen, The Phase Diagram for Magnesium-AluminiumManganese above $650{ }^{\circ} \mathrm{C}$, Z. Metallkd., 1988, 79, p 696699

61. A. Thorvaldsen and C.A. Aliravci, Solubility of Mn in Liquid Mg-Al Alloys, Proc. Int. Symp. Adv. Prod. Fabr. Light Met. Met. Matrix Comp., 1992, p 277-288

62. M. Ohno and R. Schmid-Fetzer, Thermodynamic Assessment of Mg-Al-Mn Phase Equilibira on Mg-Rich Alloys, $Z$. Metallkd., 2005, 96(8), p 857-869

63. M.S. Mirgalovskaya, L.N. Matkova, and E.M. Komova, The System Mg-Al-Mn, Trudy Inst. Met. Im. A.A. Baikova, Akad. Nauk., 1957, 2, p 139-148

64. N.V. Ageev, I.I. Kornilov, and A.N. Khlapova, MagnesiumRich Alloys of the System Magnesium-Aluminium-Manganese, Izv. Inst. Fiz.-Khim. Anal., Inst. Obshcheii Neorg. Khim., Akad. Nauk SSSR, 1948, 14, p 130-143

65. W.G. Leemann and H. Hanemann, The Ternary System Aluminium-Magnesium-Manganese, Aluminium Arch., 1938, 9, p 6-17

66. D.W. Wakeman and G.V. Raynor, The Constitution of Aluminium-Manganese-Magnesium and Aluminium-ManganeseSilver Alloys, with Special Reference to Ternary Compound Formation, J. Inst. Met., 1948, 75, p 131-150

67. H.-K. Fun, H.-C. Lin, T.-J. Lee, and B.-C. Yipp, T-Phase $\mathrm{Al}_{18} \mathrm{Mg}_{3} \mathrm{Mn}_{2}$, Acta Crystallogr., 1994, C50, p 661-663

68. J.G. Barlock and L.F. Mondolfo, Structure of Some Aluminum-Iron-Magnesium-Manganese-Silicon Alloys, $Z$. Metallkd., 1975, 66(10), p 605-611

69. T. Ohnishi, Y. Nakatani, and K. Shimizu, Phase Diagrams and Ternary Compounds of the Al-Mg-Cr and the Al-Mg-Mn Systems in Al-Rich Side, Light Met. Tokyo, 1973, 23, p 202209

70. T. Ohnishi, Y. Nakatani, and K. Shimizu, Phase Diagram in the Al-Rich Side of the Al-Mg-Mn-Cr Quaternary System, Light Met. Tokyo, 1973, 23, p 437-443

71. E. Butchers, G.V. Raynor, and W. Hume-Rothery, The Constitution of Magnesium-Manganese-Zinc-Aluminium Alloys in the Range 0-5 \% Magnesium, 0-2 \% Manganese, 0-8 \% Zinc, I-The Liquidus, J. Inst. Met., 1943, 69, p 209-228

72. A.T. Little, G.V. Raynor, and W. Hume-Rothery, The Constitution of Magnesium-Manganese-Zinc-Aluminium Alloys in the Range 0-5 \% Magnesium, 0-2 \% Manganese and 0-8 \% Zinc, III-The $500{ }^{\circ} \mathrm{C}$ and $400{ }^{\circ} \mathrm{C}$ Isothermals, J. Inst. Met., 1943, 69, p 423-440 